\title{
Using Electronic-mail Discussion Groups on the Internet to Enhance Communication in Specific Commodity Groups
}

Richard W. VanV ranken ${ }^{1}$ and Winfred P. Cowgill, J r. ${ }^{2}$

Summary. The rapid evolution of electronic technologies is providing researchers, educators, and consumers increasingly fast access to information. $0 \mathrm{n}$ the I nternet ( $\mathrm{N}$ et), electronic mail is a rapid, efficient, and economical medium for communication. M ail list management software (Listserv, Almanac, M ajordomo, and L iststar) now allows users with interests in specific topics to address production and marketing issues across state and international boundaries by posting messages to a discussion group (D G ) at one electronic address. Replies from anyone interested in responding may be sent to the entire D G, constituting a discussion, or returned directly to the originator of the message. Three commodity-oriented, horticultural DG s-AppleC rop, Veg-Prod and D irect-M kt- established over the last 30 months now provide on-line forums for $>600$ subscribers from 46 states, $4 \mathrm{C}$ anadian provinces, and 21 other countries. T wenty-seven percent to $31 \%$ of these D G s' subscribers responded to a survey evaluating the effectiveness of D G s as communication tools. Reponses showed that D G s were a valuable communication tool for reaching a broad resource pool rapidly and economically. I nformation requests, meeting announcements, and resource listings have dominated the activity of these D G s. C ooperative extension specialists and county agricultural agents represent most users $(69 \%)$, followed by researchers (14\%), farmers, and those with unlisted job descriptions ( $7 \%$ each). E ase of use, quickness (often within 24 hours), quality and quantity of replies, and the ability to glean timely information for files and newsletters were cited as the most important reasons for using these DG s.

Additional index words. apple, vegetable, direct marketing, computer, e-mail, network, Almanac, Majordomo, Listserv

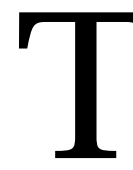

he size and scope of the Internet ( $\mathrm{N}$ et) [ $>19,000$ computer networks linking an estimated 3 million hosts with $>37$ million individuals communicating electronically on the system (Treese, 1996)] is allowing "a shift from knowledge management in the hands of the experts to knowledge access in the hands of the users" (M CLellan, 1995). C oncurrently, the role of educators is changing from distributors of information to providers of access to resources according to U SD A Acting Extension Administrator Leodry Williams in an address to participants in a $\mathrm{N}$ ational Extension Leadership D evelopment workshop (Fredericks, 1994).

\footnotetext{
${ }^{1}$ C ounty agricultural agent, $R$ utgers C ooperative Extension of A tlantic C ounty, M ays Landing, N J 08330-1533.

${ }^{2} \mathrm{C}$ ounty agent, $\mathrm{R}$ utgers $\mathrm{C}$ ooperative Extension of $\mathrm{H}$ unterdon County, Flemington, N J 08822-9058.

Wegratefully acknowledgetheassistance of $M$ artha $M$ aletta and J on Clementsin preparing thispaper. U se of tradenamesdoesnot imply endorsement of the products named or criticism of similar ones not mentioned.

The cost of publishing thispaper wasdefrayed in part by the payment of pagecharges $U$ nder postal regulations, thispaper ther eforemust be her eby marked advertisement solely to indicate this fact.
} 
Lawrence (1994) also described how the $\mathrm{N}$ et is reducing barriers to "enhanced information access" by negating the factors of distance and limited numbers of information resources available to rural Americans.

Electronic-mail (e-mail) is one tool on the $\mathrm{N}$ et that educators, researchers, and clientele are using for information access (Lawrence, 1994; Wilson, 1994). Risdon (1994) equates e-mail with the placement of messages in a personalized newspaper where only the receiver gets that part of the newspaper. Electronic discussion groups (DGs) are databases of e-mail addresses managed to al low a message sent to a single group address to be distributed simultaneously to all members of the group (Berge, 1994; K rol, 1995, Levine et al., 1995). Software designed to screen and target information is required to manage DGs on the Net (Arthur, 1993; Buckley, 1987; D ecember, 1993). D Gs began after Listserv e-mail list management softwarewaswritten for BITNET, ahardwired network of academic institutions. Listserv combinese-mail distribution with a subscription database processor. Originally developed for IBM mainframe computers, the subsequent updates of Listserv and competing list management programs (Almanac, $M$ ajordomo, Liststar) have allowed a proliferation of D G son most computer systems by correcting incompatibility problems among computers. Conveniently, most mail list management software packagesaccept similar sets of commands. (Berge, 1994; Krol, 1995; Levine et al., 1995)

Burton (1994) reviewed several advantages of D Gs for academic discussions, citing convenience (messages can be sent at the leisure of the author, and read when the recipient chooses), the ability to broadcast messages to large groups or direct them to individuals, the elimination of time and distance as barriers between sender and recipients, and removal of theneed for recipientsto be at their place of work. Although intellec- tual stimulation from wider contacts is welcomed by individuals at remote sites, Burton (1994) suggests that, compared to a face-toface conversation or phone discussion, having time to consider responses may be "the main advantage of the medium". E-mail and DGs were limited to university and government workers until the recent advent of commercial and local network providers, which now make commodity-based D G s accessible to anyone with a personal computer, telephone line, and modem (T weney, 1994).

DGs may be managed in a variety of ways. Open forums have no subscription limitations, while closed forums restrict use to members of a particular group. M essages sent to a moderated DG are routed through alist manager who may haveedito rial authority to decide the appropriateness of a message. U nmoderated $D G s$ receive messages directly from theauthor (M illes, 1994; L evine et al., 1995)

C ontinually updated directories of D Gs indicate a wide range of topics can be discussed on-line, but the number of DGs devoted to horticulture and agriculture is small (Shaffer et al., 1993; Balraj, 1995; N eou 1995). D airy-L, created in 1990, was one of the first agriculturally oriented D Gs (Varner and Cady, 1993). After participating in online $N$ et training offered by extension service (ES)-U SDA and realizing the potential to network efficiently and at low cost with colleagues beyond state borders, we initiated D Gs to complement our areas of interest and expertise.

Thispaper summarizesasubscriber evaluation of these $D \mathrm{Gs}$. R esponses echo the reaction found by Varner and Cady (1993) to Dairy-L. Also presented are modifications suggested by the survey responses and current directions for accessing the $D G s$.

\section{Materials and methods}

Since October 1993, we established, modified, and are managing three topic-fo-

Table 1. Subscription statistics as of $\mathbf{1 0 / 9 5}$ and current participation directions for three horticultural electronic discussion groups.

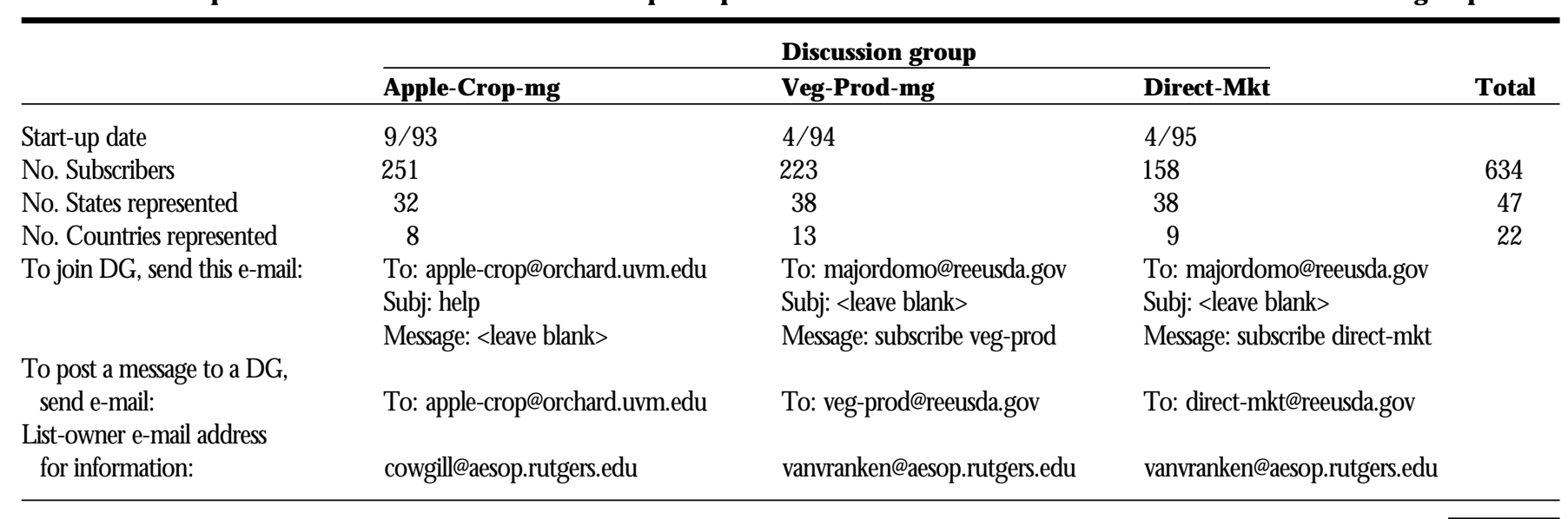




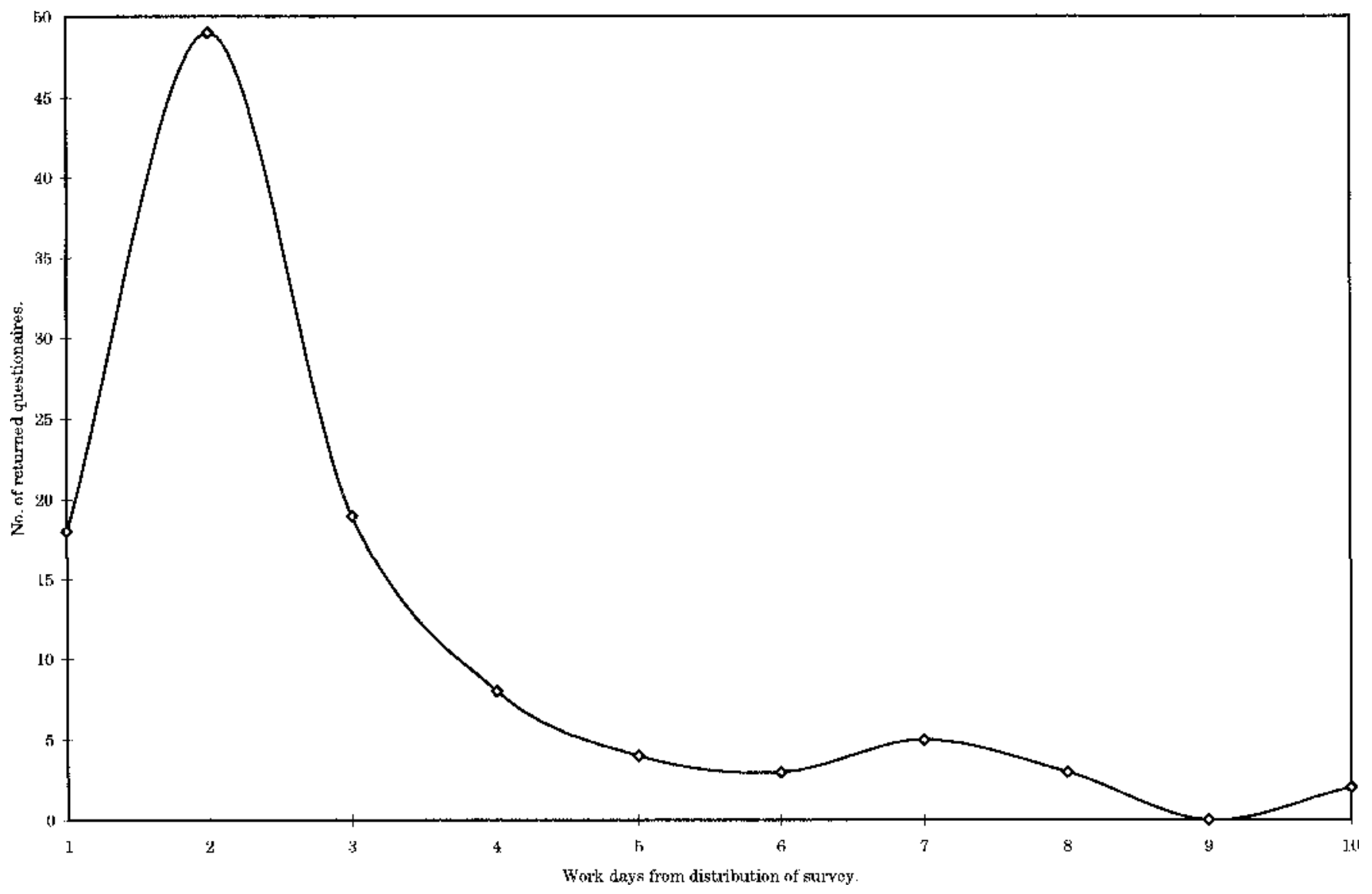

cused DGs to facilitate rapid exchange of information among colleagues working on apple production, vegetable production, or direct marketing. D G sneed a host computer housing mail list management software. ESU SD A program leaders for horticulture and marketing approved proposals to develop Apple-Crop-mg, Veg-Prod-mg, and D irect$M$ kt on the U SD A computer system. A ppleCrop-mg and Veg-Prod-mg were started using Almanac mail list management software at the ES-U SD A site (almanac@esusda.gov), while D irect-M kt went on-line in early 1995 using $\mathrm{M}$ ajordomo mail list software at the new cooperative research education and extension service(REEU SD A) site (majordomo @reeusda.gov). In D ecember 1995, the vegetable production DG was renamed VegProd and moved to the REEU SDA M ajordomo host. Shortly thereafter, the apple D G
Fig. 1. Speed of response to e-mail survey of VegProd-mg and Direct-Mkt DGs.

was renamed Apple-Crop and sited on a dedicated personal computer server using Liststar DG management software at the Univ. of Vermont (apple-crop@orchard. uvm.edu). Although the host address and directionsfor development and management are slightly different for the various list management software packages, the steps for joining and participating in the DGs are basically the same. Table 1 describes the current directions for joining and participating in these three DGs.

Potential participants were prompted to join Apple-Crop-mg, Veg-Prod-mg, and Direct-M kt by distributing invitations through traditional modes of communication: wordof-mouth, direct and e-mail to individuals,

T able 2. I nternet and discussion group activity of survey respondents.

\begin{tabular}{|c|c|c|c|c|}
\hline & \multicolumn{3}{|c|}{ Discussion group } & \multirow[b]{2}{*}{ Total } \\
\hline & Apple-Crop-mg & Veg-Prod-mg & Direct-M kt & \\
\hline M ean no. D Gs respondents subscribe to: & 4 & 3 & 4 & 3 \\
\hline No. respondents who have sent messages to $D G$ : & 40 & 40 & 15 & 95 \\
\hline M ean no. messages sent/ respondent sending messages to $D G$ : & 4 & 3 & 7 & 5 \\
\hline M ean no. responses received/ message sent: & 10 & 5 & 15 & 10 \\
\hline
\end{tabular}


conference presentations (Cowgill, 1994), and news releases to trade journals and other D Gs. A nalysis of all e-mail addresses on each DG's subscription list (O ctober 1995-beforethe recent host site changes) revealed the number of subscribers and their geographic distribution, also summarized in Table 1. The three groups were surveyed at that time; an identical evaluation form was distributed electronically to participants to gain an understanding of the usefulness of these D G sin providing forums for communication.

\section{Results and discussion}

M orethan 600 subscribersfrom 46 states, $4 \mathrm{C}$ anadian provinces, and 21 other countries had joined Apple-Crop-mg, Veg-Prod-mg, and D irect-M kt as of O ctober 1995. Each DG also had 20 or more subscribers through private $\mathrm{N}$ et service providers, and messages posted to two of the DGs were redistributed to other discussion groups of unknown size. While the subscription list for D irect-M kt reached $>200$ by April 1996, the new Veg-

T able 3. Evaluation of discussion groups by subscribers.

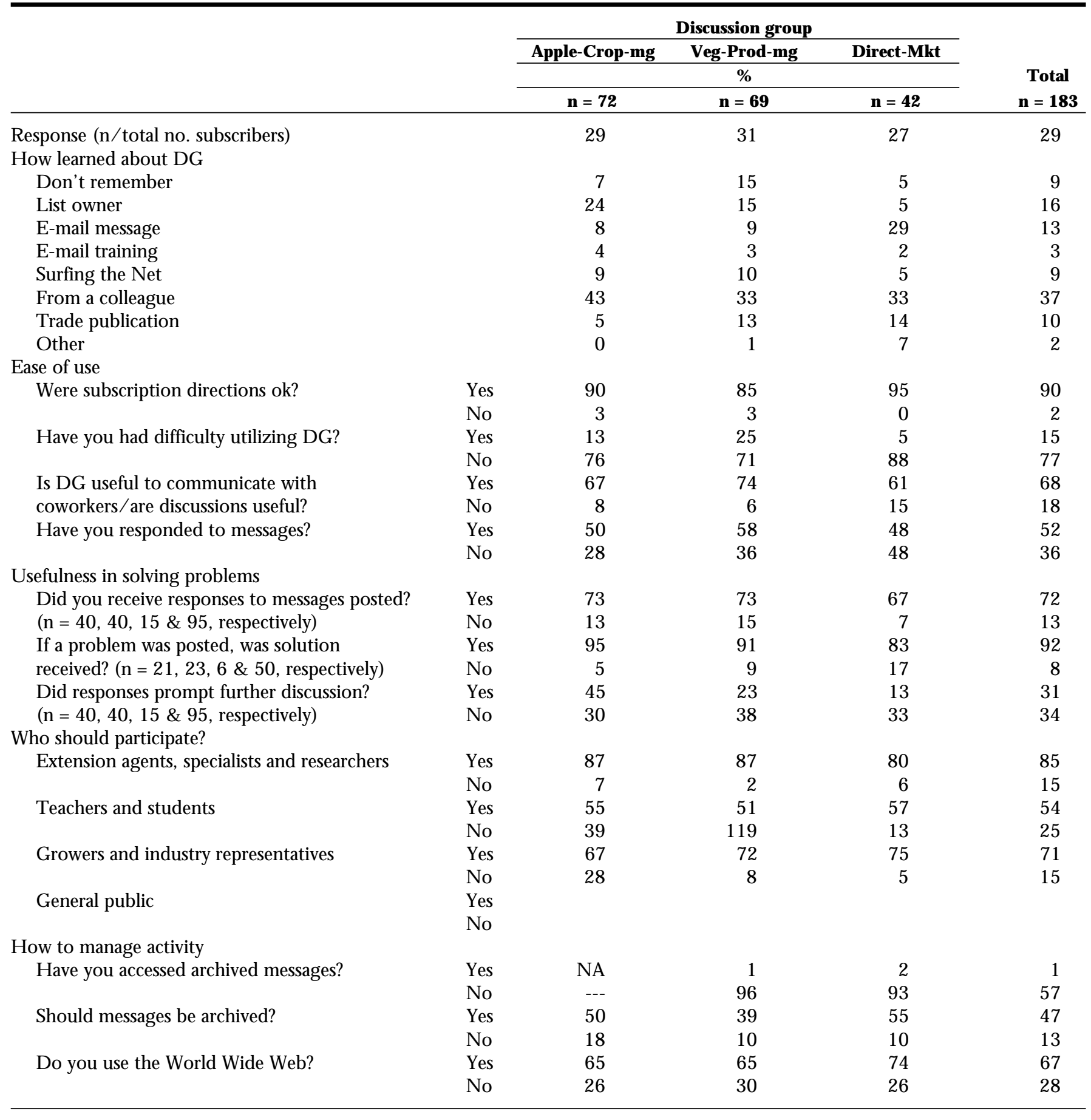


Prod and Apple-Crop DGs experienced a $20 \%$ to $30 \%$ drop in subscriptions during the transition to their new hosts. $\mathrm{H}$ owever, the numbers of subscribers to all three groups continue to grow daily.

One of the most common comments received regarding use of $D G$ s was that questions were answered quickly. For example, the first person to reply did so within $25 \mathrm{~min}$ of distribution of the survey questionnaire, and most responses were returned within 2 working days of the original posting (Fig. 1).

The survey received a $29 \%$ response $(n=$ 183), which is summarized in T ables 2 and 3. Extension specialists and agents returned the largest number of surveys (Fig. 2). T able 2 indicates how heavily subscribers to AppleCrop, Veg-Prod, and D irect-M kt use e-mail DGs. Participants in these three DGs subscribe to a mean of 3 to $4 \mathrm{DG}$ s and receive a mean of 15 messages per day overall. Slightly more than half of all respondents (52\%) had sent messages to the D G and they had sent a mean of 5 messages per respondent.

Of greater importance is the usefulness of the DGs for solving problems (Table 3). Seventy-two percent of those sending messages indicated responses were received. A mean of 10 responses were received per message sent. The number of responses received appeared to depend on the type of message sent. Specific questions received 1 to 12 responses, whileannouncements of new publications or resources received 12 to 150 requests to obtain the product. $\mathrm{H}$ owever, those sending questions to the $D G$ received solutions to the problem they were investigating $92 \%$ of the time.

Table 3 also indicates the response regarding the ease of use of these DGs was generally favorable. $N$ inety percent indicated the directions for participating in the DGs were adequate. 0 f the $10 \%$ not indicating the directionswereadequate, $7 \%$ did not respond to the question, $1 \%$ did not remember, and the remaining $2 \%$ indicated they would like to see directions posted at regular intervals as reminders, or that they couldn't remember how to reply to messages to the entire group. Sixty-eight percent responded that the DGs were useful tools for communicating with other workers in the same field. Comments regarding the usefulness of the discussions and the value of communications indicate participants joined these DGs to tap the expertise of specialists and to network with co-workers they would not contact otherwise, to glean information for newsletters or reference files for later use, and to keep informed of timely issues affecting the respective industries.

Three areas of concern surfaced in the evaluations: a higher number of Veg-Prod$\mathrm{mg}$ participants indicated having problems using the DG, the question of who is responsible to answer questions posted, and the volume of activity on each DG.

M ost problems with using Veg-Prod$\mathrm{mg}$ were related to the many undeliverable messages returned to a sender. This is partly a management function to remove bad addresses from the subscription list if they become recurring problems. H owever, comments like, "I tsvaluehas been worth far more than the annoyance of getting returned messages," indicate that participants are willing to live with a degree of frustration. $\mathrm{H}$ ardware overload may be a potential problem as the popularity of the $\mathrm{N}$ et soars faster than the system can be updated to manage the traffic. The sheer volume of messages may create occasional hardwareoverloadsblocking transmission to and through certain nodes on the system.

Posting a message to a DG, although quick and easy, is a shotgun approach to getting a response that depends on who is listening and who cares to reply. As one extension specialist noted, responding to all, or even a good portion, of the queries posted to a DG would increase the user's workload significantly. While tapping a large and expe-

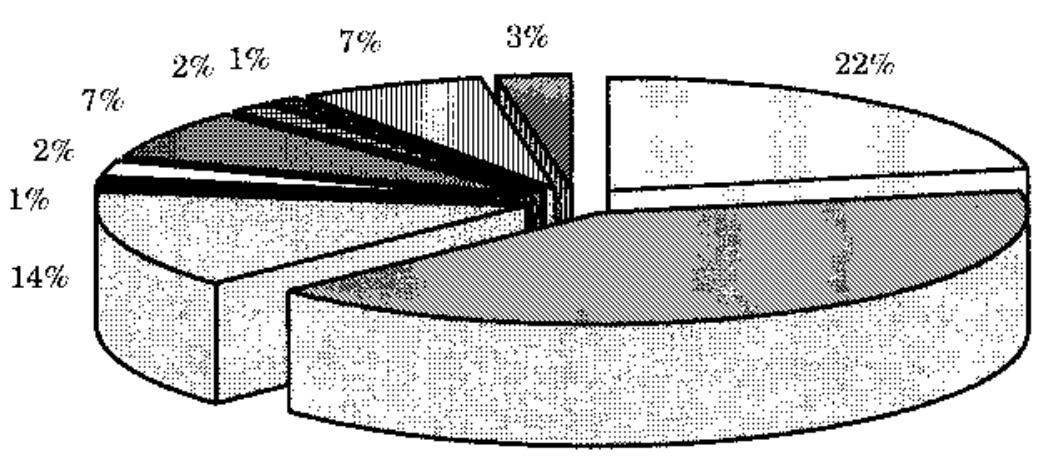

$41 \%$
DAgent

Specialist

$\square$ Researcher

Teacher

口Student

Farmer

䧃Industry Rep

EGen. Public

mother

国 $\mathrm{NA}$ 
rienced resource base, there is no guarantee that anyone will take the time to respond. This is not borne out in these DGs, as indicated by thenumber of responses to messages received per inquiry and the fact that most problems were solved by those responses.

The most consistently reported concern was the potential burden of too much activity in a D G. Participants in the three D Gs surveyed indicated they already subscribe to an average of three other DGs and receive, on average, 15 mail messages per day. The highs for the groups were 75 messages per day, and 24 DG subscriptions, although these were not from the same respondent. There were several comments suggesting users would like to see more discussions, more research reports, and responses to questions posted to the entire group. $\mathrm{H}$ owever, there was greater concern over creating too much volume. This was most evident in the answers to whom should be invited to participate: extension specialists and agents received the greatest number of "yes" replies compared to other suggested groups; the general public was the only group to receive more "no" than "yes" replies. Theseoften wereaccompanied bycomments such as, "the discussion is too technical," "keep it on a professional/ academic level," and "thereareother forums[D Gs] for discussing home gardening topics."

\section{Conclusion}

Based on the survey responses, comments, and suggestions, the Veg-Prod DG has been transferred to its new host site and is experiencing increased appropriate activity since the user survey was completed. Part of the overload problem experienced in late 1995 involved misuse of the D G by nonsubscribers to send lengthy advertisements, the electronic equivalent of junk mail, which can be time consuming and expensive for subscribers. The switch to Majordomo has stopped this misuse of $\mathrm{Veg}$-Prod to date, but Apple-Crop may have a better deterrent. Liststar software allows only subscribers to post messages to the $D G$.

Consistent with the number of subscriberswho indicated they areaccessing theW orld Wide Web (WWW), Apple-Crop has been, and eventually D irect-M kt and $V$ eg-Prod will be, integrated into existing or new WWW servers. Clements (1995) and Cowgill initiated an apple production WWW home page, The Virtual Orchard (VO), at <http:/ / orchard.uvm.edu/ $>$. I t iso perated on a dedicated personal computer, a M acintosh 6150 Power PC Server. VO provides for the dissemination of information over the Internet on all aspects of sustainable apple production. VO will also house WWW pages for research projects dealing with apples and other tree fruit production and marketing issues, such as the N C-140 Regional Rootstock Project and the NE-183 Regional Apple Cultivar Trial.

With the formation of this WWW site, Apple-C rop D G activity has been enhanced with the addition of interactive forums on specific topics. The topics are selected by the VO site managers Clements and Cowgill. In addition to this powerful communication tool, DG activity is being expanded into multimedia formats beyond text messages. On-line participants can post digital color photographs, formatted documents, and video clips. TheWWW format givesindividuals the ability to view graphics and text documents on-line, download and print them while maintaining all original formatting, or continue to exchange text messages. A multimedia database on the WWW also can contain a searchable file of frequently asked questions (FAQS) as requested by one survey respondent.

While indicating high interest in adopting evolving electronic communication technologies for the horticulture industry, participant evaluations of three commodity-specific horticultural e-mail D Gs support previous work (Varner and Cady, 1993; Burton, 1994) that DGs are easy, convenient, costeffective means of networking with others having similar interests. Although many respondents indicated they would like to see a greater exchange of news and more responses to specific questions, some expressed, consistently with L evine's et al. (1995) suggestions for "Netiquette", concern that too much volume or misuse would jeopardize participation by those the DGs were designed to serve. To date, Apple-Crop, Veg-Prod, and $D$ irect-M kt have been low volume, professional forums for rapid exchange of commodity-specific information around the world.

\section{Literature Cited}

Arthur, C. 1993. Zen and the art of ignoring information. Info. Soc. 9(1):51-60.

Balraj, L. 1995. Agriculture, veterinary science and zoology. In: D.K. Kovacs (ed.). Directory of scholarly E-conferences. 9th rev. (Archived at ftp:/ / zeus. kent.edu/ library/ acadlistorgopher:/ / gopher.usask.ca/ 1/ Computing/ Internet I nformation/ D irectory of ScholarlyE lectronic C onferences.)

Berge, Z. L. 1994. Electronic discussion groups. Commun. Educ. 43(2):102-111.

Buckley, F.J. Jr. 1987. Knowledge access issues. Info. Soc. 5(1):45-50.

Burton, P. F. 1994. Electronic mail as an academic discussion forum. J. D ocumentation 50(2):99-110.

Clements, J . 1995. Personal communication. U niv. 
of Vermont, D ept. of Plant Science, Burlington.

Cowgill, W.P., Jr. 1994. U pdate on Apple Crop $\mathrm{Mg}$, the Internet discussion group on apple production. Proc. 70th Cumberland-Shenandoah Fruit W orkersC onf., H ort. Section, Virginia T ech Agr. Res. and Ext. Center, Winchester, Va., 17-18 Nov.

D ecember, J . 1993. I nformation sources: The Internet and computer-mediated communication. Release 3.15. (Archived at ftp:/ / rpi.edu/ pub/ communications/ Internet-cmc.txt.)

Fredericks, E.E. 1994. Extension leader describes significant changes in education...going from delivery of information to access to information. J. Agr. Food Info. 2(2):115-117.

K rol, E. A dapted by R. Petrusha. 1995. The whole Internet user's guide. Version 2.0. O 'Reilly \& Associates, Inc., Sebastopol, C alif. p. 204-209.

Lawrence, G. W. 1994. Information poor, information rich: rural America and the Internet. J. Agr. Food Info. 2(3):71-81.

Levine, J. R ., C. Baroudi and M. Levine Young. 1995. The Internet for dummies. 3rd ed. IDG Books Worldwide, Inc., Foster City, Calif.

McLellan, M.R. 1995. Electronic information management: A model for industry, academia, and IFT. Food T echnol. 49(3):74, 76-78, 80-81, 96.

Milles, J . 1994. D iscussion lists: M ail server commands. (Archived at ftp:/ / sluaxas.slu.edu/ pub/ millesjg/ mailser.cmd.)
$\mathrm{N}$ eou, V. 1995. Internet mailing lists navigator. Prentice H all. (A rchived at mail-server@sri.com as interest-groups.txt.)

R isdon, P. 1994. T ransferring technology through the Internet channel. J. Ext. 32(1) (Electronic journal archived at almanac@joe.org/ send joe 1994 catalog.)

Shaffer, D., R. Booker, W. Cowgill, Jr., D. D ay, L. M oorman, Mark Spelbring and R. VanVranken. 1993. Extension educator's catalog of agricultural resources available through I nternet. N atl. Assn. of County Agr. Agents, 1993 Annu. M eeting. Baltimore, Md. (Archived at gopher:/ / esusda.gov/ extension service, U SD A/ I nternet services and information/ cooperative extension system:/ guides to the Internet/ extension educator's catalog of agricultural resources.)

Treese, W. 1996. N umber of people over 16 with accessto thel nternet. I nternet I ndex 1(12). (http:/ / www.openmarket.com/ intindex/ 96-01.htm.)

Tweney, D. 1994. The traveler's guide to the information highway. Z iff D avis Press, E meryville, Calif.

Varner, M. and R. Cady. 1993. D airy-L: An electronic information exchange network for professionals advising dairy producers. J. Dairy Sci. 76(8):2325-2331.

Wilson, P.S. 1994. M eeting the information needs of the extension agent. J. Agr. and I nfo. 2(3):6569.

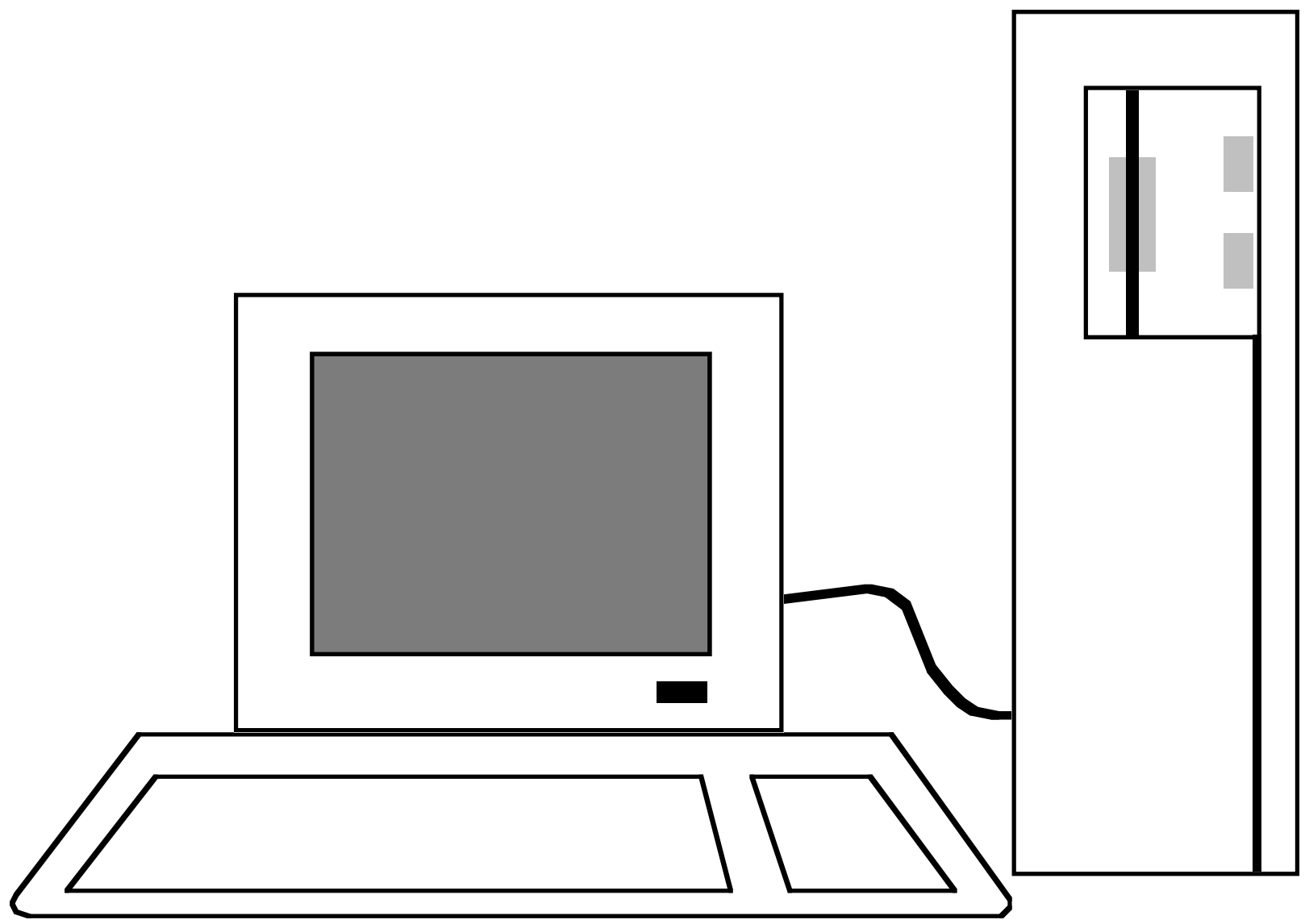

